\title{
DEBATES
}

\section{A insatisfação política e a ascensão do autoritarismo- populista: uma análise da América do Sul e da Europa}

\author{
Political dissatisfaction and the rise of authoritarian-populism: an \\ analysis of South America and Europe
}

\section{Henrique Carlos de Oliveira de Castro \\ Débora de Oliveira Santos \\ Luana Isabelle Beal}

\section{Resumo}

Nos últimos anos, observamos a ascensão de atores autoritário-populistas tanto em democracias consolidadas quanto naquelas ainda não bem estabelecidas. Neste artigo, analisamos se o aumento da insatisfação política explica o crescimento do apoio político ao autoritarismo-populista na América do Sul e na Europa. Nossa hipótese é que um ambiente de insatisfação política explica o fenômeno. Analisamos os casos da Alemanha, Argentina, Brasil, Chile, Espanha e Holanda. Utilizamos dados do World Values Survey e dos resultados eleitorais de 2005 a 2019. Verificamos que há uma desconexão entre o apoio à democracia e a insatisfação com o seu desempenho, o que favorece, em alguns casos, o crescimento do autoritarismo-populista. Além disso, os eleitores desses atores são os mais insatisfeitos. Porém, a hipótese é parcialmente confirmada, já que a insatisfação é insuficiente para explicar todos os casos, sendo outros fatores, como o conflito de valores e a cultura política, mais pertinentes.

\section{Palavras-chave}

Autoritarismo; Populismo; Insatisfação Política; América do Sul; Europa.

\begin{abstract}
In the past few years, we have seen the rise of authoritarian-populist actors, both in consolidated democracies and in those that are not yet well established. In this article, we analyze whether the increase of political dissatisfaction explains the growth in political support for populist authoritarianism in South America and Europe. We hypothesize that an environment of political dissatisfaction explains this phenomenon. We analyzed the cases of Germany, Argentina, Brazil, Chile, Spain and the Netherlands. We used data from the World Values Survey and electoral results, from 2005 to 2019. We verified that there is a disconnection between support for democracy and dissatisfaction with its performance, which favors, in some cases, the growth of authoritarianpopulism. Besides that, those who vote for these actors are more dissatisfied. However, the hypothesis is partially confirmed, since dissatisfaction is insufficient to explain all cases, while other factors, such as the conflict of values and political culture, are more relevant.
\end{abstract}

\section{Keywords}

Authoritarianism; Populism; Political Dissatisfaction; South America; Europe. 


\section{Introdução}

Mundialmente, observamos a presença cada vez mais expressiva de movimentos e atores políticos que reivindicam a volta de valores tradicionais, por bandeiras radicais anti-imigração e por políticas mais conservadoras (KYLE e GULTCHIN, 2018). Com uma retórica populista e valores, comportamentos e atitudes autoritários, candidatos e partidos políticos têm ascendido politicamente, mobilizando as massas a partir de discursos iliberais, antidemocráticos e antissistema, sobretudo vinculados ao espectro ideológico da direita, como podemos observar, por exemplo, na Europa e na América do Sul.

Para explicar a irrupção desse fenômeno, Norris e Inglehart (2019) apontam para a presença de um ponto de inflexão, chamado de cultural backlash, nas sociedades ocidentais de capitalismo avançado e com sistemas democráticos já bem estabelecidos. Segundo os autores, há uma contraposição entre valores pósmaterialistas e valores conservadores na cultura política dessas sociedades que é mobilizada na disputa política do mercado eleitoral. Embora Norris e Inglehart (2019) tenham explicado o fenômeno em países desenvolvidos de democracia já avançada, a ascensão do autoritarismo-populista tem atingido, também, países da América do Sul, com democracias ainda inerciais (BAQUERO, 2018) e valores mais materialistas (INGLEHART e WELZEL, 2014).

Considerando a extensão desse fenômeno, buscamos analisá-lo a partir da insatisfação política, que é um importante fator na desconexão democrática e no apoio a alternativas autoritárias (FOA e MOUNK, 2016). Assim, nosso objetivo é verificar se, em países europeus e sul-americanos nos quais há um aumento da insatisfação política, houve também maior apoio a políticos autoritário-populistas. A hipótese é de que o aumento da insatisfação política, na dimensão da demanda no mercado eleitoral, cria uma desconexão entre sociedade e política que gera um ambiente propício à ascensão de alternativas autoritário-populistas na dimensão da oferta.

Para verificar se o ambiente de insatisfação política pode configurar-se como uma condição comum em países da Europa e da América do Sul, analisamos dados longitudinais do World Values Survey (WVS) no período de 2005 a 2019. A seleção de países teve como critérios a disponibilidade de dados para o período e a presença de atores autoritário-populistas em eleiçóes recentes, sendo eles: Alemanha, Argentina, Brasil, Chile, Espanha e Holanda. Especificamente, analisamos as dimensôes de apoio à democracia e confiança institucional, o desempenho eleitoral e a intenção de voto. 
Além da introdução e da conclusão, este artigo está dividido em quatro seçôes. $\mathrm{Na}$ primeira, discutimos o cultural backlash, a mobilização eleitoral da reação autoritária e as limitaçóes desta explicação. $\mathrm{Na}$ segunda, discutimos a insatisfação política e a desconexão democrática como explicação ao apoio a alternativas autoritárias e, portanto, à ascensão autoritário-populista. Na terceira, apresentamos a metodologia empregada neste artigo, a base de dados, os casos selecionados e as variáveis analisadas. E, na quarta seçáo, analisamos os dados de apoio à democracia e confiança institucional, sua relação com o crescimento eleitoral de atores autoritáriopopulistas nos países analisados, e também o quão insatisfeitos são os eleitores desses partidos e candidatos.

\section{A ascensão autoritário-populista num contexto de conflito de valores}

Segundo Norris e Inglehart (2019), a retórica populista baseia-se em: (i) desafiar a autoridade legítima do establishment, questionando as crenças de governos eleitos democraticamente; e (ii) legitimar-se como "poder das pessoas comuns", como única fonte de autoridade e moral, dando voz aos "cidadãos comuns", mesmo quando contrariando a legalidade democrática. Já culturas autoritárias baseiam-se: (i) na distinção entre "Nós" e "Eles", ou seja, no compartilhamento de uma identidade comum de valores e atitudes; e (ii) em retratar ameaças à segurança do grupo, em que intrusos e políticos não são confiáveis e a única proteção é a força, caracterizando-se pela intolerância.

Embora a rejeição populista às elites estabelecidas possa ligar-se a políticas liberais progressistas, frequentemente esse discurso acompanha e enfatiza valores autoritários. Essa junção de populismo com autoritarismo corrói o pluralismo, as proteçóes das liberdades individuais, os direitos das minorias, a transparência e a separação de interesses pessoais e políticos. Nesse sentido, coloca o Estado como instrumento do governo e tem como alvos a grande mídia, a validade das eleiçóes, os partidos políticos, a burocracia estatal, o sistema judiciário, a ciência e as organizações internacionais (NORRIS e INGLEHART, 2019). A ascensão súbita de atores autoritário-populistas nas eleições recentes abala o desempenho político dessas sociedades. Além desse movimento estar presente em países subdesenvolvidos, constata-se que ele também ocorre em países com democracia consolidada.

Essas sociedades ocidentais economicamente desenvolvidas e democraticamente consolidadas experimentaram, no pós-Guerras, uma mudança 
cultural para valores pós-materialistas e seculares-racionais (DALTON e WELZEL, 2014; INGLEHART e WELZEL, 2014; INGLEHART, 2018). A menor preocupaçáo com a segurança econômica e física aumentou a segurança existencial, e coortes etárias mais jovens passaram a possuir valores relacionados com a liberdade individual e a autoexpressão, em detrimento de valores tradicionais e de sobrevivência (INGLEHART e WELZEL, 2014). Com isso, questôes que não faziam parte do espaço público e político passaram a integrar tanto valores, atitudes e comportamentos quanto a agenda política, como: proteçáo ambiental, direitos humanos, igualdade de gênero, diversidade sexual, direitos de imigrantes, de pessoas com deficiência e de minorias étnico-raciais.

Essas mudanças culturais relacionam-se com processos estruturais de modernização que ocorreram desde a segunda metade do século $\mathrm{XX}$, como fluxos migratórios, expansão do acesso aos níveis superiores de ensino, maior igualdade de gênero e processos de urbanização (INGLEHART e WELZEL, 2014). Porém, eventos conjunturais também produzem efeitos de período, mobilizando determinados valores culturais. Segundo Norris e Inglehart (2019), a recessão econômica, a crise dos refugiados e os atos de terrorismo na Europa são efeitos de período que têm inibido a evoluçáo em direçáo a valores mais liberais. Esses eventos favoreceram uma reação autoritária de públicos que, insatisfeitos com os problemas conjunturais, buscam reforçar a ideia de uma Europa com valores de conformidade social, ordem e estabilidade.

Segundo Norris e Inglehart (2019), essa reação autoritária é um ponto de inflexão gerado pela disputa social e política entre valores liberais e conservadores, outrora hegemônicos. Para os públicos conservadores, os valores pós-materialistas são imorais, decadentes, ameaçam valores tradicionais e precisam ser contidos (NORRIS e INGLEHART, 2019). Logo, o cultural backlash reforça identidades tradicionais como a fé, a família e a nacionalidade; identidades que, embora hegemônicas no século XX, não são mais dominantes nas sociedades ocidentais contemporâneas.

Esse conflito de valores se reflete na ascensão de atores autoritário-populistas nos últimos anos. Embora os conservadores tenham perdido seu status hegemônico em relação aos valores presentes nas sociedades, eles continuam sendo uma parcela significativa da população e a maioria votante (NORRIS e INGLEHART, 2019). Diferentemente das coortes mais jovens, com valores mais liberais, que se engajam em formas não convencionais de participação política; coortes mais velhas e mais conservadoras são ativas em atividades convencionais, como o voto (DALTON e WELZEL, 2014; NORRIS e INGLEHART, 2019). Com isso, conservadores são 
desproporcionalmente influentes nas eleiçóes, e um grupo-alvo para elites políticas que veem uma oportunidade no ressentimento e na raiva desses grupos. Com a reconfiguração dos issues políticos para questôes culturais (FREIRE, 2001), observase um aumento na polarização das identidades sociais, dividindo a opiniáo pública entre "Nós" e "Eles" e estimulando o cultural backlash, canalizado por partidos, líderes e movimentos autoritário-populistas (NORRIS e INGLEHART, 2019) por intermédio de discursos que culpam elites liberais, políticos corruptos e a mídia tradicional.

Embora os elementos trazidos por Norris e Inglehart (2019) contribuam para explicar a ascensão autoritário-populista, o limite geográfico e cultural dos autores não compreende a amplitude do fenômeno, sobretudo porque buscam explicá-lo em países de economia e democracia desenvolvidas. Porém, ao longo da década de 2010, observamos a ascensão de líderes e movimentos autoritário-populistas ao redor do mundo todo, inclusive em sociedades com valores materialistas e tradicionais (KYLE e GULTCHIN, 2018). Com efeito, a extensão da explicação para outras regiôes do planeta deve ser feita com parcimônia, porque, de acordo com Castro $(2019)^{1}$, não se pode falar em retrocesso cultural em países da América Latina porque não chegamos lá. Portanto, é necessário buscar elementos comuns nos casos em que o populismoautoritário ascendeu, e uma explicação pode estar na insatisfaçáo política.

\section{Insatisfação politica, desconexão democrática e a ascensão autoritário-populista}

Diferentemente da explicação proposta por Norris e Inglehart (2019), Foa e Mounk (2016) apontam que a perda da confiança da população em relação à democracia e o crescimento do apoio às alternativas de regime não democráticas sáo os principais indícios da desconexão democrática, que atinge tanto as democracias já consolidadas quanto aquelas menos estáveis. $\mathrm{O}$ momento de instabilidade enfrentado por democracias contemporâneas caracteriza-se pela diminuiçáo do apoio à democracia, insatisfação e desinteresse da população em relação à política, presença de partidos antissistema e adoção de estratégias não democráticas pelos atores

\footnotetext{
${ }^{1}$ Comunicação verbal em mesa-redonda na 72a conferência anual da Wapor, onde membros da World Values Survey Association discutiram sobre valores democráticos e prognósticos para democracias contemporâneas, que são diversas em termos de consolidação do sistema político, de desenvolvimento econômico e de cultura política, mesmo que enfrentando desafios semelhantes (DEMOCRACY..., 2019).
} 
tradicionais. Assim, mesmo que a democracia ainda seja o sistema político com maior apoio popular, ela "[...] perdeu a confiança de muitos cidadãos que já não acreditam que a democracia possa atender suas preferências e necessidades mais prementes" (FOA e MOUNK, 2016, p. 19). Isso acontece porque o apoio manifesto ao sistema político democrático é difuso (EASTON, 1968), sem que as pessoas necessariamente reflitam a respeito.

Segundo Castro (2014), a abstração do conceito de democracia, bem como o valor positivo que a palavra carrega, leva a população a aceitá-la mesmo sem saber exatamente o que ela significa. Por isso, o apoio à democracia pode coexistir com valores autoritários, com ambivalência política e com concepçôes divergentes sobre a função das lideranças de instituiçôes e partidos políticos (FOA e MOUNK, 2016; MOISÉS, 2008). Porém, essa contradição provoca uma desconexão entre a cultura política e o regime democrático em si. $\mathrm{Na}$ falta de congruência entre esses dois aspectos, a democracia fica vulnerável à insatisfaçáo política e às iniciativas antidemocráticas, principalmente em momentos em que há um desequilíbrio entre as demandas sociais e as respostas políticas produzidas para satisfazê-las.

Assim, a insatisfação política tem um papel importante no contexto de ascensão de líderes de partidos autoritário-populistas. Por um lado, a insatisfaçáo assume a forma de frustração com o desempenho dos governos democráticos e atores tradicionais, com avaliaçóes negativas das ações do poder político. Foa e Mounk (2016) indicam que isso pode erodir o apoio ao sistema político democrático e aumentar o apoio a alternativas autoritárias. Empiricamente, observa-se que essa insatisfação com o desempenho de governos democráticos pode ser instrumentalizada por lideranças políticas e traduzida em votos contrários ao poder vigente (GUNTHER e MONTERO, 2003). E isso tem sido, no contexto contemporâneo, mobilizado principalmente por atores que pautam políticas antissistema.

Por outro lado, a insatisfação política também se manifesta na falta de confiança em relação às instituiçôes democráticas. A confiança institucional é um importante atributo na dinâmica democrática, que sustenta a legitimidade das democracias. Segundo Moisés e Meneguello (2013), a presença da confiança institucional depende de uma harmonia entre os interesses e as demandas da sociedade e o desempenho institucional em políticas públicas eficazes e satisfatórias. Embora a literatura da cultura política indique que a confiança institucional não é produzida pelas próprias instituiçóes, e sim um resultado de valores e atitudes socialmente compartilhados (ALMOND e VERBA, 1963; INGLEHART, 1977; LOPES, 2004), sua ausência também pode refletir aspectos da conjuntura política. 
A falta de confiança é observada quando as demandas da sociedade não são correspondidas ou são correspondidas de forma ineficaz. Em contextos de instabilidade política, social ou econômica, o mau desempenho institucional gera quadros de desconfiança na população que são dificilmente reversíveis pelas próprias instituiçóes, gerando um círculo vicioso (POWER e JAMISON, 2005). A desconfiança é um elemento presente principalmente em sociedades com passados autoritários, cujo papel centralizador do Estado limitou a cidadania e a socialização de valores de confiança nas instituiçôes e processos democráticos vigentes (BAQUERO, RANINCHESKI e CASTRO, 2018). Nesse sentido, estudos recentes sobre o Brasil apontam que a crise de representaçáo política e a desaceleração econômica estão associadas ao crescimento da insatisfação política e à ascensão autoritário-populista (DUARTE et al., 2020).

Além de impactar negativamente a legitimidade e o apoio difuso à democracia, a falta de confiança institucional favorece também o surgimento e a ascensão de partidos e movimentos políticos antidemocráticos, e cria um ambiente de desconexão democrática, favorável para o apoio a formas autoritárias de regime político (FOA e MOUNK, 2016; GUNTHER e MONTERO, 2003; MOISÉS e MENEGUELLO, 2013). Essa insatisfação, ainda, é observada em diferentes públicos: entre pós-materialistas insatisfeitos porque veem poucas mudanças ocorrendo, e entre materialistas insatisfeitos porque defendem a conservação da ordem social estabelecida (INGLEHART, 1977); bem como em sociedades cuja democracia já é consolidada, como nos Estados Unidos e na Europa (FOA e MOUNK, 2016), e em sociedades cuja democracia ainda é inercial, como no Brasil (BAQUERO, 2018).

Ainda, a relação entre o público e as instituições democráticas alterou-se bastante nas últimas décadas com a intensificação dos dilemas sociais e políticos (LOPES, 2004). Os complexos problemas políticos, econômicos e sociais enfrentados pelas democracias contemporâneas, além de resultarem em efeitos de período, também erodem a confiança nas instituiçóes e o apoio à democracia, num contexto cada vez mais interdependente, globalizado e desigual. Estas características conjunturais, globalmente compartilhadas, exigem maior cooperaçáo social e política quanto às normas e estruturas institucionais, em elementos como regras democráticas, competição eleitoral, princípios de liberdade e igualdade, cidadania e ética nas funções institucionais (MOISÉS e MENEGUELLO, 2013). 
A carência dessa cooperação num ambiente complexo, interdependente e desigual promove o crescimento da desconfiança e a fragilização do sistema democrático, com o declínio da identificação partidária, a menor mobilização dos partidos e menores taxas de comparecimento às eleiçóes (FOA e MOUNK, 2016). Ainda, a insatisfação com a política pode reduzir a solidariedade social e diminuir o apoio à democracia e suas instituiçôes, gerando descontentamento com a política governamental e o menor apoio às autoridades que regulamentam a atividade eleitoral (LOPES, 2004). Isso alimenta a circulação de discursos iliberais, antissistemas e antidemocráticos, típicos de atores autoritário-populistas. Portanto, a insatisfação com a política pode ser uma condição comum na demanda do mercado eleitoral que explicaria o apoio a políticos autoritário-populistas em diferentes contextos sociais e culturais.

\section{Metodologia}

Para analisar se em sociedades europeias e sul-americanas nas quais houve um aumento da insatisfação política há também um aumento no apoio a atores autoritário-populistas, utilizamos o método comparativo. Este método é adequado em pesquisas que buscam analisar a existência ou não de um dado fenômeno em sociedades distintas ou semelhantes, especialmente em estudos comparados de Cultura Política, que usam grandes amostras de dados de surveys (GONZÁLEZ, 2008).

Os países da América do Sul e da Europa possuem diferenças significativas. Por um lado, as culturas políticas dessas duas regióes diferem: os países sulamericanos, em geral, possuem valores tradicionais e de sobrevivência, enquanto países europeus, majoritariamente, têm valores seculares-racionais e de autoexpressão (INGLEHART e WELZEL, 2014) ${ }^{2}$. Por outro, as trajetórias históricas também se diferem, e se refletem, ainda hoje, no quanto os países dessas regiôes são social e economicamente desenvolvidos ou não. Considerando isso, adotamos o Desenho de Sistemas Mais Diferentes (SARTORI, 1991).

Realizamos uma análise longitudinal, com dados do período de 2005 a 2019, correspondente às três últimas ondas do WVS. A escolha dos casos teve como critérios: (i) o país, europeu ou sul-americano, estar presente nas ondas analisadas; (ii)

\footnotetext{
${ }^{2}$ Existem evidências de que os valores seculares-racionais e de autoexpressão na América Latina são relativamente maiores do que se esperaria, tendo em vista a situação de vida material das populaçóes da regiáo. Castro et al. (2020) apresentam uma explicaçáo alternativa para essa aparente dissociação.
} 
o país, europeu ou sul-americano, possuir partidos ou candidatos autoritáriopopulistas que concorreram a eleiçóes recentes. Assim, os países selecionados são: Alemanha, Argentina, Brasil, Chile, Espanha e Holanda. Analisando os programas políticos dos atores políticos que concorreram a eleiçóes recentes nesses países, selecionamos os atores autoritário-populistas segundo a definição de Norris e Inglehart (2019), são eles: na Argentina, Juan José Gómez Centurión e a Frente NOS; na Alemanha, a Alternative für Deutschland (AfD); no Brasil, Jair Bolsonaro e o Partido Social Liberal (PSL); no Chile, José Antonio Kast e o Unión Demócrata Independiente (UDI); na Espanha, o VOX; e, na Holanda, o Partij voor de Vrijheid (PVV) e o Forum voor Democratie (FvD) ${ }^{3}$.

Analisamos a insatisfaçáo política por meio da confiança institucional e do apoio à democracia, com as variáveis: confiança no governo, nos partidos políticos e no parlamento; importância da democracia; apoio ao sistema político democrático; e satisfação com a performance do sistema político do país. Já o apoio político a atores políticos autoritário-populistas foi analisado por intermédio do desempenho eleitoral e da intenção de voto, com as variáveis: número de votos ou assentos obtidos em eleiçóes; e intenção de voto declarada.

\section{Entre a demanda e a oferta no mercado eleitoral: a insatisfação política dos eleitores e a ascensão autoritário-populista}

Embora o conflito de valores explique a ascensão do autoritarismo-populista nos países de democracia consolidada e economia desenvolvida, o fenômeno escapa desse limite geográfico. Buscamos reformular o enfoque por meio da insatisfaçáo política, usada como um indicador da desconexão democrática que favorece a ascensão de atores autoritário-populistas. Nesta seção, apresentamos os resultados para este enfoque, subdivididos em três partes. Na primeira, analisamos a insatisfaçáo política na demanda. Na segunda, analisamos a oferta, com o desempenho eleitoral de autoritário-populistas. Por fim, na terceira, analisamos a insatisfação política entre os eleitores desses atores em comparaçáo com os eleitores de outros partidos.

\footnotetext{
3 Existem duas limitaçóes neste levantamento: (i) na Argentina, os atores analisados surgiram recentemente, e há dados apenas para a última eleição realizada no país; (ii) no Chile, além do partido UDI, há o Partido Republicano, criado em 2019 por José Antonio Kast, ex-UDI, e que ainda não concorreu a nenhum pleito eleitoral, não sendo incluído nesta análise.
} 
108 | Henrique Carlos de Oliveira de Castro, Débora de Oliveira Santos e Luana Isabelle Beal

\section{A insatisfação politica na dimensão da demanda}

Para análise dos dados sobre a insatisfação política, recodificamos os valores das variáveis utilizadas. $\mathrm{Na}$ variável de apoio ao sistema político democrático, para o "apoio" somou-se os valores das respostas de "ótimo" ou "bom"; e para o "não-apoio" os valores das respostas de "ruim" ou "péssimo". Nas variáveis de importância da democracia e de satisfação com a performance do sistema político, que possuem escala de 1 a 10, calculamos a média das respostas. Nos gráficos abaixo, estáo os resultados para essas variáveis.

Figura 1 - Apoio ao sistema político democrático

\section{Sistema político democrático}

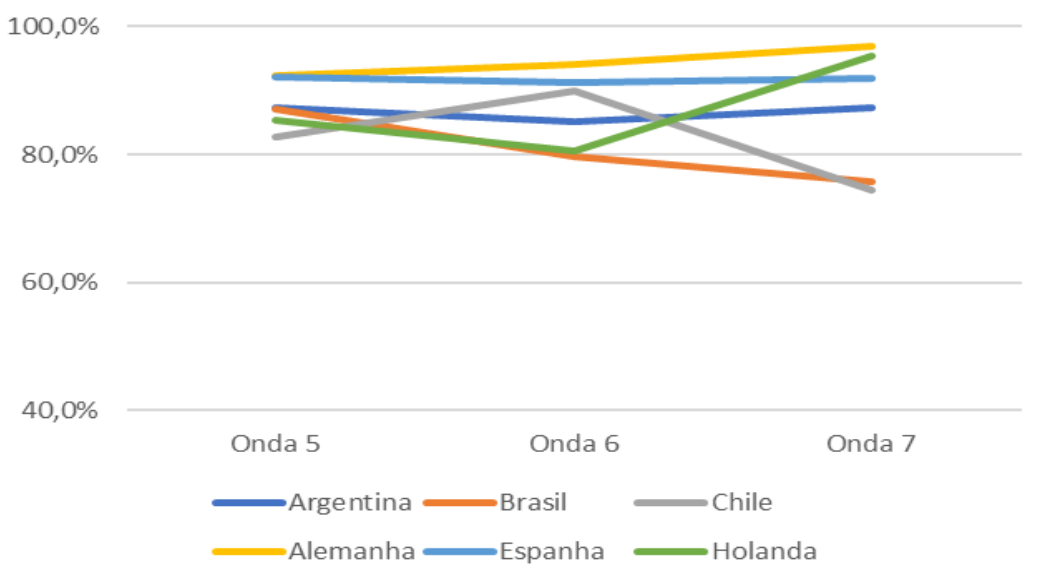

Fonte: Elaborado pelos autores com base nos dados do WVS. 
Figura 2 - Importância da democracia

\section{Importância da democracia}

10

6

4

2

0
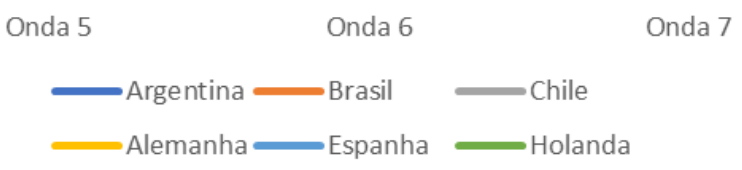

Fonte: Elaborado pelos autores com base nos dados do WVS.

Figura 3 - Satisfação com a performance do sistema político do país
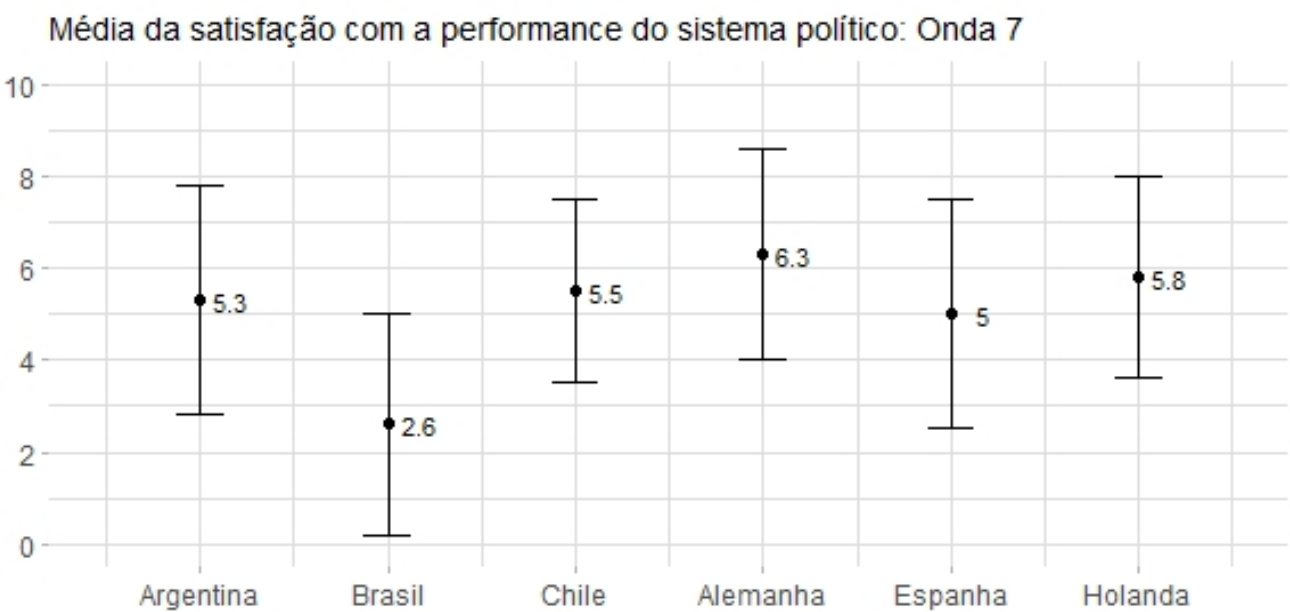

Fonte: Elaborado pelos autores com base nos dados do WVS.

Os resultados acima indicam que o apoio à democracia é alto em todos os países analisados. Observamos níveis altos nas variáveis de importância da democracia e de apoio ao sistema político democrático. Porém, os resultados variam nas variáveis de apoio e de satisfaçáo com a performance da democracia. No Brasil, o apoio ao 
110 | Henrique Carlos de Oliveira de Castro, Débora de Oliveira Santos e Luana Isabelle Beal

sistema político democrático caiu $11,5 \%$ entre as Ondas 5 e 7; no Chile, 15,6\% entre as Ondas 6 e 7; e na Holanda houve uma queda de 8\% entre as Ondas 5 e 6, com recuperação de 15,3\% nas ondas seguintes. Ademais, a satisfação com o desempenho do sistema político não apresenta resultados positivos, sobretudo no Brasil - a menor média entre os casos analisados - e na Espanha - a menor média para os países europeus.

Isso indica, principalmente, o que Castro (2014) e Foa e Mounk (2016) já apontaram sobre a existência de um apoio abstrato à ideia da democracia, mas que não necessariamente se reflete na satisfação da população sobre o desempenho democrático. Portanto, para compreender melhor o quadro de insatisfaçáo política, analisamos a confiança institucional. Nos gráficos abaixo estão os resultados para as variáveis de confiança no governo, no parlamento e nos partidos políticos, para as respostas de "confia muito" ou "confia".

Figura 4 - Confiança no Governo

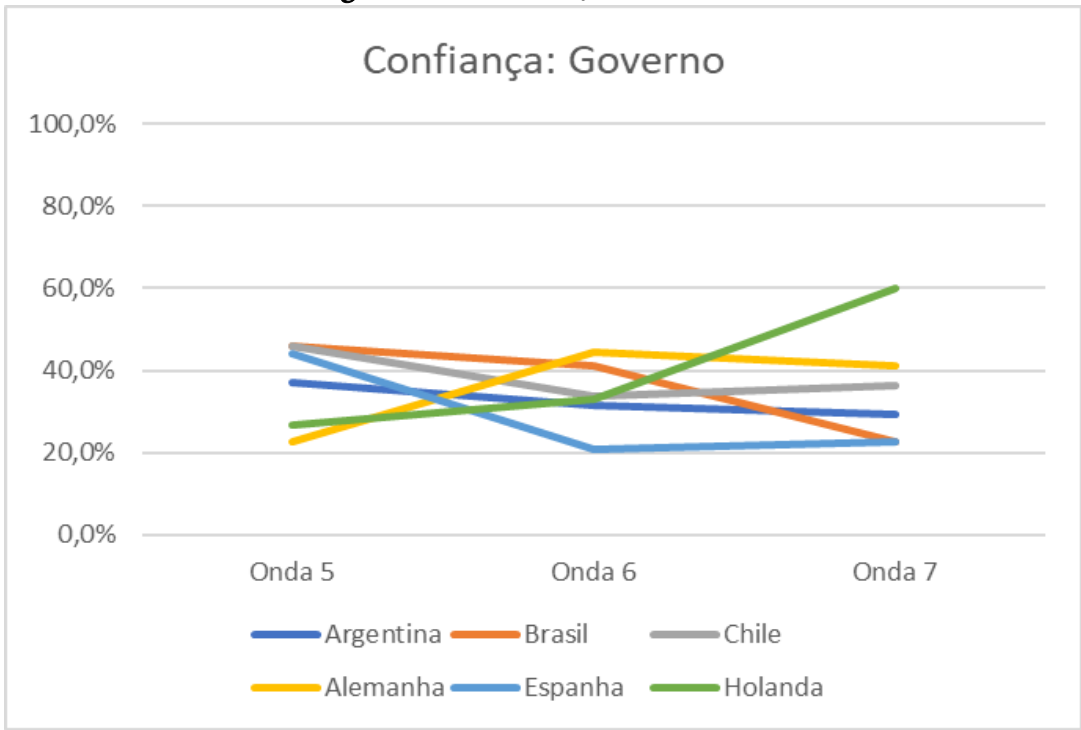

Fonte: Elaborado pelos autores com base nos dados do WVS. 
Figura 5 - Confiança nos partidos políticos

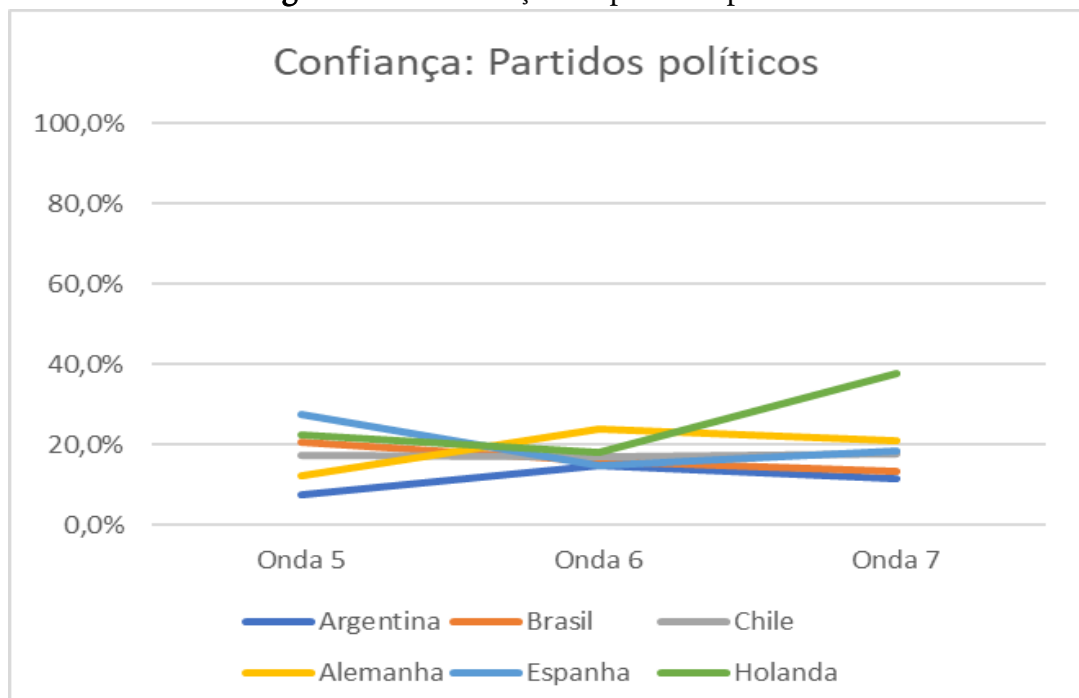

Fonte: Elaborado pelos autores com base nos dados do WVS.

Figura 6 - Confiança no Parlamento

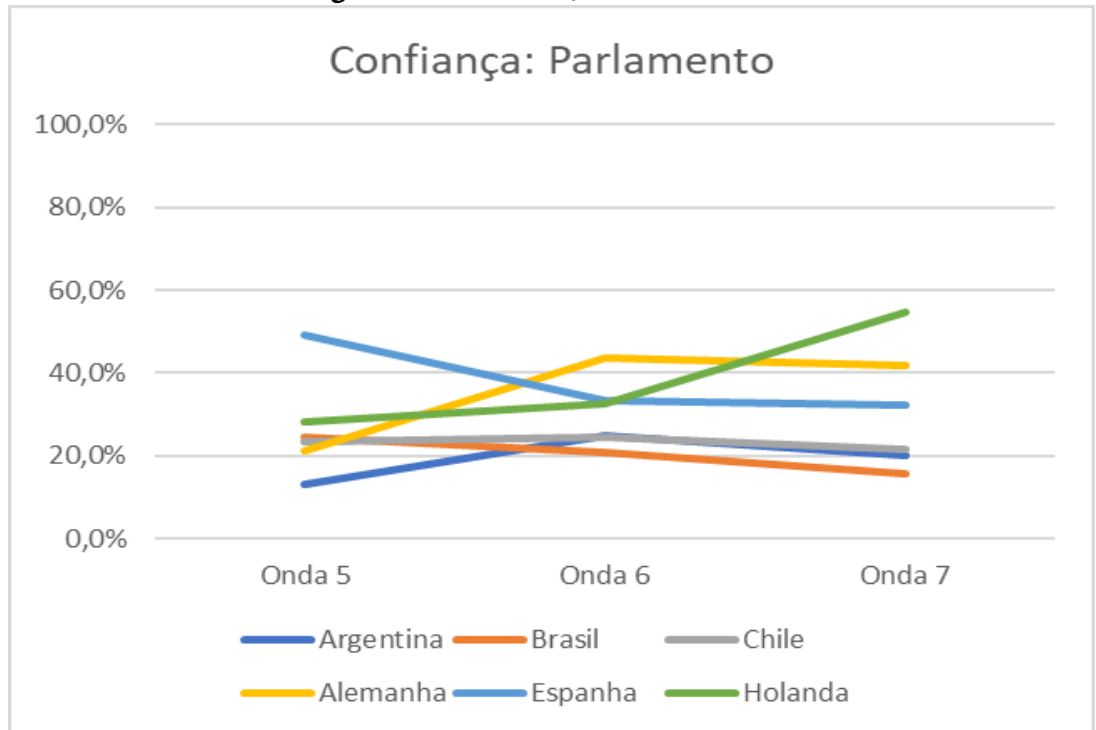

Fonte: Elaborado pelos autores com base nos dados do WVS.

Os resultados indicam a instabilidade da confiança institucional no período analisado. Por um lado, nota-se que há maior confiança no parlamento em países europeus do que entre países sul-americanos. Isso se explica pelos diferentes desenhos 
institucionais dos países das duas regióes, no quanto o parlamento participa na direçáo do poder político ou se a divide com um Poder Executivo independente (CHEIBUB, 2007). Por outro, destacam-se a instabilidade na confiança no governo e a baixa confiança nos partidos políticos nestes países.

A confiança no governo é um indicador importante da satisfação com o desempenho institucional, refletindo a avaliação negativa ou positiva da população sobre as açóes governamentais frente à conjuntura política e econômica (PUTNAM, LEONARDI e NANETTI, 1988). Nesse sentido, chama a atenção a queda significativa da confiança no governo no Brasil, respondendo com descrédito aos cenários de crise política e econômica da década de 2010; na Espanha, que enfrenta um cenário de instabilidade econômica; e a recuperaçáo da confiança no governo na Alemanha e na Holanda, bem sucedidos na retomada econômica pós-crise de 2008.

Já a baixa confiança nos partidos políticos em todos os países chama a atenção, tendo em vista que os partidos políticos são uma instituição mediadora considerada essencial ao funcionamento democrático, responsável por aglutinar interesses da sociedade e traduzi-los em políticas públicas. As altas taxas de rejeição indicam a desconexão democrática nas duas regióes, e como o processo de enfraquecimento da identificação e da filiação partidárias tem, inclusive, levado os cidadãos a apoiarem menos os partidos políticos tradicionais, favorecendo a retórica antissistema de partidos autoritário-populistas (FOA e MOUNK, 2016).

Em suma, esses resultados indicam que, embora o apoio abstrato à democracia seja forte, os cidadãos já não estão mais satisfeitos com o sistema político e não confiam nas respostas dadas pelas suas instituiçóes aos problemas conjunturais. Assim, diante de turbulências políticas e econômicas, a opiniáo pública parece estar responsabilizando as instituiçôes democráticas pelos problemas enfrentados, mas sem reprovar a democracia em si. Constata-se um ambiente de desconexão entre sociedade e política, de incongruência entre instituiçóes e cultura política, que é propício ao surgimento e à ascensão de atores iliberais, antidemocráticos e antissistema.

\section{O apoio politico a autoritário-populistas na dimensão da oferta}

Com base nesse panorama sobre a insatisfação política na dimensão da demanda, analisamos o apoio político aos autoritário-populistas. Para tanto, verificamos o desempenho eleitoral destes atores políticos, com um levantamento baseado nas porcentagens nas votaçóes e número de assentos obtidos em casas legislativas no período de 2005 a 2019. No quadro abaixo, um resumo desse levantamento. 
Quadro 1 - Atores políticos autoritário-populistas e desempenho eleitoral

\begin{tabular}{|c|c|c|}
\hline PAÍSES & ATORES POLÍTICOS & DESEMPENHO ELEITORAL \\
\hline \multirow[t]{2}{*}{ Argentina } & Juan José Gómez Centurión & $\begin{array}{l}\text { Eleiçóes presidenciais de } 2019: 5^{\circ} \text { lugar nas eleiçóes } \\
\text { presidenciais, com } 1,71 \% \text { dos votos. }\end{array}$ \\
\hline & $\begin{array}{l}\text { Frente NOS (Coalizão em } \\
\text { 2019) }\end{array}$ & $\begin{array}{l}\text { Eleiçốes gerais de 2019: Não elegeu deputados nem } \\
\text { senadores. }\end{array}$ \\
\hline \multirow[t]{3}{*}{ Brasil } & Jair Bolsonaro & $\begin{array}{l}\text { Eleiçóes presidenciais de } 2018: 46,03 \% \text { dos votos no } \\
\text { primeiro turno e } 55,13 \% \text { no segundo turno; eleito } \\
\text { presidente. }\end{array}$ \\
\hline & \multirow{2}{*}{$\begin{array}{l}\text { PSL (Partido criado em } \\
\text { 1994) }\end{array}$} & Eleições gerais de 2010: 1 deputado federal. \\
\hline & & $\begin{array}{l}\text { Eleiçôes gerais de 2019: Elegeu } 52 \text { deputados federais } \\
\text { e } 4 \text { senadores. }\end{array}$ \\
\hline \multirow[t]{5}{*}{ Chile } & José Antonio Kast & $\begin{array}{l}\text { Eleiçóes presidenciais de 2017: 4o lugar nas eleiçôes } \\
\text { presidenciais, com 7,93\% dos votos. }\end{array}$ \\
\hline & \multirow[t]{4}{*}{$\begin{array}{l}\text { UDI (Partido criado em } \\
1988)\end{array}$} & $\begin{array}{l}\text { Eleiçôes gerais de 2005: Elegeu } 33 \text { deputados e } 9 \\
\text { senadores. }\end{array}$ \\
\hline & & $\begin{array}{l}\text { Eleiçôes gerais de 2009: Elegeu } 37 \text { deputados e } 8 \\
\text { senadores. }\end{array}$ \\
\hline & & $\begin{array}{l}\text { Eleiçóes gerais de 2013: Elegeu } 29 \text { deputados e } 8 \\
\text { senadores. }\end{array}$ \\
\hline & & $\begin{array}{l}\text { Eleiçốes gerais de 2017: Elegeu } 30 \text { deputados e } 9 \\
\text { senadores. }\end{array}$ \\
\hline \multirow[t]{3}{*}{ Alemanha } & \multirow{3}{*}{$\begin{array}{l}\text { AfD (Partido criado em } \\
\text { 2013) }\end{array}$} & Eleiçôes gerais de 2017: 94 deputados eleitos. \\
\hline & & Eleiçôes europeias de 2014: Elegeu 7 deputados. \\
\hline & & Eleiçóes europeias de 2019: Elegeu 11 deputados. \\
\hline \multirow[t]{4}{*}{ Espanha } & \multirow{4}{*}{$\begin{array}{l}\text { VOX (Partido criado em } \\
\text { 2013) }\end{array}$} & Eleiçōes gerais de 2015: Não elegeu deputados. \\
\hline & & Segunda eleição geral de 2019: Elegeu 52 deputados. \\
\hline & & Eleições europeias de 2014: Não elegeu deputados. \\
\hline & & Eleições europeias de 2019: Elegeu 4 deputados. \\
\hline
\end{tabular}


114 | Henrique Carlos de Oliveira de Castro, Débora de Oliveira Santos e Luana Isabelle Beal

\begin{tabular}{|c|c|c|}
\hline \multirow[t]{9}{*}{ Holanda } & \multirow{6}{*}{$\begin{array}{l}\text { PVV (Partido criado em } \\
\text { 2006) }\end{array}$} & Eleiçôes de 2010: Elegeu 24 deputados. \\
\hline & & Eleições de 2011: Elegeu 10 senadores. \\
\hline & & Eleiçôes de 2017: Elegeu 20 deputados. \\
\hline & & Eleições de 2019: Elegeu 5 senadores. \\
\hline & & Eleiçôes europeias de 2014: Elegeu 4 deputados. \\
\hline & & Eleições europeias de 2019: Elegeu 1 deputado. \\
\hline & \multirow{3}{*}{$\begin{array}{l}\text { FvD (Partido criado em } \\
\text { 2016) }\end{array}$} & Eleiçóes de 2017: Elegeu 2 deputados. \\
\hline & & Eleiçôes de 2019: Elegeu 12 senadores. \\
\hline & & Eleiçôes europeias de 2019: Elegeu 3 deputados. \\
\hline
\end{tabular}

Fonte: Elaborado pelos autores.

Com este levantamento, verificamos que, em todos os países, há o crescimento eleitoral desses atores políticos nos últimos 15 anos. Dentre os casos analisados, o Brasil é o caso sul-americano que se destaca. O país, que já possuía uma baixa confiança institucional (BAQUERO, 2018; MOISÉS, 2008), apresentou a maior queda de confiança no governo federal no período analisado (-22\%), e uma queda significativa no apoio ao sistema político democrático (-11\%). Paralelamente, o Brasil passou por uma conturbada conjuntura política, saindo da sucessão de presidentes do Partido dos Trabalhadores (PT), para o impeachment da ex-presidente Dilma Rousseff (PT) e findando na eleição de Jair Bolsonaro à presidência da república e na eleição de 52 deputados federais e quatro senadores do seu antigo partido ${ }^{4}$.

Bolsonaro foi eleito em 2018 num complexo processo eleitoral, caracterizado pela judicializaçáo, moralizaçáo, fake news e polarização política. Seu discurso antissistema, conservador e autoritário conseguiu canalizar as insatisfaçóes crescentes da população, descrente e ressentida com os atores políticos tradicionais. Bolsonaro conseguiu também mobilizar aspectos autoritários da cultura política brasileira, como a nostalgia da ditadura (CASTRO, 2014; BITTENCOURT, 2020) e o apoio a

\footnotetext{
${ }^{4}$ No momento das eleiçóes de 2018, Bolsonaro estava filiado ao PSL. Saiu do partido em 2019, com o objetivo de criar seu próprio partido, o Aliança Brasil. Até o momento em que este artigo foi elaborado, o Aliança Brasil não foi fundado, e Bolsonaro permanece sem partido (LIMA, 2020).
} 
sistemas políticos não democráticos (SANTOS et al., 2020), aspectos estes que não foram superados pelos anos de vivência democrática (BAQUERO e GONZÁLEZ, 2016).

Já na Espanha, que foi o caso europeu com maior queda na confiança no governo $(-18 \%)$ e no parlamento $(-15 \%)$, houve também um crescimento no apoio eleitoral ao VOX, com a eleição de 52 deputados na segunda eleição de 2019 para o Parlamento espanhol. Em virtude do fracasso do Partido Socialista Operário Espanhol (PSOE) em formar um governo nas eleiçóes de abril de 2019, a Espanha teve novas eleiçóes em novembro. Entre os pleitos, o VOX cresceu em 24 assentos (CUÉ, 2019). O partido angariou votos da população mais pobre e da classe trabalhadora, explorando as desigualdades existentes, a esperança por melhorias e o medo e ressentimento sobre condiçóes socioeconômicas vigentes (CAPARRÓS, 2019).

Com o slogan "tornar a Espanha grande de novo", emprestado do presidente estadunidense Donald Trump, o VOX rejeita o rótulo de extrema-direita sob o argumento de que representa o que pensam milhóes de espanhóis. Recorrendo à moralidade e ao nacionalismo, o discurso do partido é voltado a valores conservadores, contrários a pautas como o aborto e o casamento entre pessoas do mesmo sexo, tendo buscado, inclusive, reverter a legislação de proteção à violência de gênero, alegando que ela discrimina homens. Além disso, o VOX também possui uma postura anti-imigração e contra a independência catalá, mas, diferente da onda autoritária-populista europeia, o partido apoia a adesão da Espanha à União Europeia (HEDGECOE, 2019).

Brasil e Espanha confirmam a hipótese deste trabalho de que a presença de um ambiente de insatisfação política cria um cenário propício para a ascensão desses atores políticos. Esses resultados dialogam com a ideia de que o sistema democrático precisa ter confiança (MOISÉS e MENEGUELLO, 2013; LOPES, 2004), e que a insatisfação política é um fator que favorece a presença de atores antidemocráticos, antissistema e iliberais (FOA e MOUNK, 2016; GUNTHER e MONTERO, 2003). Porém, outros casos possuem resultados menos conclusivos, o que impede a generalização da hipótese.

No Chile, a queda na confiança no governo, no apoio ao sistema democrático e na importância da democracia náo se traduziu em votos ao candidato José Antonio Kast, nem em mais assentos ao UDI nas eleiçóes parlamentares. Sebastián Piñera, eleito presidente em 2017, teve, porém, o UDI em sua coligação e fez uma campanha 
que mobilizou a insatisfação da população chilena com a conjuntura do país (CUÉ e MONTES, 2017; MANDER, 2017). Além disso, o Chile possui uma particularidade na alternância política. Desde 2006, Michelle Bachelet e Sebástian Piñera substituíram um ao outro na presidência. Além da ausência de reeleições, nem Bachelet nem Pińera elegeram seus indicados, levando à alternância sucessiva entre a centro-esquerda e centro-direita nos últimos 15 anos.

Assim, no Chile, observamos o papel das regras institucionais e da dinâmica político-partidária na contenção de atores autoritário-populistas. Por um lado, Piñera cooptou a insatisfação da população, apropriando-se de demandas que estariam disponíveis a Kast, o que se aproxima do que Norris e Inglehart (2019) apontam para o Partido Conservador no Reino Unido. Porém, o UDI manteve bom desempenho eleitoral no congresso. Esse cenário corresponde àquilo que outros autores já apontaram sobre a cultura política chilena, que mantém, ao mesmo tempo, a rejeição do passado autoritário e atitudes ambivalentes em relação à democracia (CASTRO, 2014; COSTA e GONZÁLEZ, 2019).

$\mathrm{Na}$ Argentina, observamos forte desconfiança nos partidos políticos e no parlamento, mas isso também não gerou sucesso eleitoral para Juan José Gómez Centurión e sua coalizão. Dois fatores podem explicar isso. O primeiro é a dinâmica político-partidária na Argentina e as heranças da formação social e política do país. $\mathrm{O}$ peronismo presente no imaginário político argentino, e sua renovaçáo com o kirchnerismo no início do século XXI produz identidades políticas que ainda influenciam a dinâmica político-partidária e que não foram superadas pela polarização política e pelo liberalismo do ex-presidente Mauricio Macri (ALONSO e BRUSSINO, 2018; REYNA, 2007).

O segundo é que Gómez Centurión é uma figura controversa, dissociada de uma Argentina com pautas progressistas. Ex-militar, veterano da Guerra das Malvinas e conservador, o candidato negou publicamente fatos da ditadura militar argentina (JUAN JOSÉ..., 2017), resultado em denúncias de apologia ao crime (LA JUSTICIA..., 2017). A rejeição de Gómez Centurión é explicada pela deslegitimação do papel político dos militares argentinos (COSTA e GONZÁLEZ, 2019) e pela alta satisfação com o sistema político democrático e estável apoio à democracia. $\mathrm{Na}$

\footnotetext{
${ }^{5}$ Desde 2005, os movimentos feministas têm estado fortemente presentes na política argentina. Em 2015, os protestos "Ni una menos", contra a violência doméstica, eclodiram no país. Nos últimos dois anos, com a votação da lei que autoriza o aborto legal, a Marea Verde ou Ola Verde tomou as ruas de várias cidades (BRIEGER, 2018; UNA RENOVADA..., 2020).
} 
Argentina, a contenção a esses atores ocorre tanto por meio da dinâmica partidária quanto pela própria cultura política, que reprova discursos antidemocráticos pela rejeição ao passado autoritário.

$\mathrm{Na}$ Alemanha, encontramos forte confiança institucional e apoio à democracia, com a maior média de satisfação com o sistema democrático. Porém, na contramão da hipótese deste trabalho, também observamos um crescimento no apoio à AfD. Criado em 2013, o partido se tornou a quarta força política no parlamento alemáo em 2017, e o quinto partido alemáo com mais assentos no Parlamento Europeu nas eleições de 2019. Uma explicação no caso alemão é o crescente conflito social e cultural, dadas as crises econômica e migratória, que revelam uma tendência autoritária. Nessas condiçóes, a Alemanha corresponde ao cultural backlash, de Norris e Inglehart (2019), em que a principal explicação para o fenômeno reside, principalmente, no conflito entre valores materialistas e pós-materialistas. $\mathrm{O}$ apoio a esses atores não seria reflexo de uma desconfiança com as instituiçôes, e sim da latência do conflito social e cultural, mobilizado a partir de valores tradicionais e nacionalistas. Nesse caso, não se trata somente de insatisfação política, mas da mobilização das clivagens culturais no mercado eleitoral.

E, por fim, o caso da Holanda chama atenção já que o país teve quedas na confiança institucional e no apoio ao sistema político democrático, mas que foram recuperadas. Essa recuperação é concomitante à redução do apoio eleitoral ao PVV, que perdeu cinco assentos no senado entre 2011 e 2019, e três no parlamento europeu de 2014 a 2019. Porém, nesse período, um novo partido ascendeu - o FvD é o principal ator político autoritário-populista do país e o maior partido no Senado holandês em 2019 (FVD..., 2019).

A extrema-direita na Holanda é um fenômeno recente e tem mobilizado o nacionalismo como resposta às ameaças à segurança, cultura, religiáo e bem-estar (DAMHUIS, 2019; GHITIS, 2019). Os partidos se distinguem em algumas pautas: o PVV, com discursos anti-imigraçáo e anti-islamismo; e o FvD defendendo o liberalismo econômico, a negação das mudanças climáticas e o apelo à democracia direta. Esses partidos políticos, porém, têm utilizado de valores pós-materialistas para justificar pautas radicais. No seu discurso anti-islamismo, o PVV ressalta valores progressistas, como tolerância e pautas de gênero, contra o que definem como intolerante, sexista e homofóbico na cultura islâmica (DAMHUIS, 2019). Assim, a Holanda contradiz a tese do cultural backlash já que a ascensão do autoritarismopopulista mobiliza valores pós-materialistas. 
118 | Henrique Carlos de Oliveira de Castro, Débora de Oliveira Santos e Luana Isabelle Beal

\section{A insatisfação politica entre os diferentes eleitorados}

Por fim, analisamos o quáo insatisfeitos politicamente sáo os públicos que declararam que votariam em candidatos e partidos autoritário-populistas. Nas Tabelas 1 e 2, apresentamos os resultados do cruzamento de dados entre as variáveis de intenção de voto, confiança institucional e apoio à democracia. Cabe ressaltar que, pela ausência de dados de intenção de voto para a Frente NOS e o VOX, não há resultados para Argentina e Espanha.

Tabela 1 - Desconfiança institucional e intenção de voto em autoritário-populistas

Tabela de referência cruzada: Desconfiança Institucional e Intenção de Voto

\begin{tabular}{l|r|r|r|r|r|r|r|r|c}
\hline País & \multicolumn{2}{|c|}{ Chile } & \multicolumn{2}{c|}{ Brasil } & \multicolumn{2}{c|}{ Alemanha } & \multicolumn{3}{c}{ Holanda } \\
\hline $\begin{array}{l}\text { Intençáo de } \\
\text { voto }\end{array}$ & UDI & Outros & Bolsonaro & Outros & AfD & Outros & PVV & FvD & Outros \\
\hline $\begin{array}{l}\text { Governo } \\
\text { federal }\end{array}$ & $74,0 \%$ & $62,9 \%$ & $79,3 \%$ & $74,1 \%$ & $92,8 \%$ & $56,0 \%$ & $81,1 \%$ & $77,1 \%$ & $44,3 \%$ \\
\hline $\begin{array}{l}\text { Partidos } \\
\text { políticos }\end{array}$ & $70,3 \%$ & $82,5 \%$ & $92,2 \%$ & $82,0 \%$ & $95,7 \%$ & $77,3 \%$ & $96,2 \%$ & $81,9 \%$ & $71,5 \%$ \\
\hline Parlamento & $69,3 \%$ & $77,5 \%$ & $85,1 \%$ & $80,3 \%$ & $92,7 \%$ & $53,5 \%$ & $87,4 \%$ & $83,4 \%$ & $50,5 \%$ \\
\hline
\end{tabular}

Fonte: Elaborado pelos autores com base nos dados do WVS.

Tabela 2 - Apoio à democracia e intenção de voto em autoritário-populistas

Tabela de referência cruzada: Apoio à Democracia e Intençáo de Voto

\begin{tabular}{l|r|r|r|r|r|r|r|r|r}
\hline País & \multicolumn{2}{|c|}{ Chile } & \multicolumn{2}{c|}{ Brasil } & \multicolumn{2}{c|}{ Alemanha } & \multicolumn{3}{c}{ Holanda } \\
\hline Intençáo de voto & UDI & Outros & Bolsonaro & Outros & AfD & Outros & PVV & FvD & Outros \\
\hline $\begin{array}{l}\text { Apoio ao sistema } \\
\text { político } \\
\text { democrático }\end{array}$ & $92,3 \%$ & $77,3 \%$ & $86,8 \%$ & $89,9 \%$ & $97 \%$ & $98,7 \%$ & $91,8 \%$ & $97,2 \%$ & $96,2 \%$ \\
\hline $\begin{array}{l}\text { Importância da } \\
\text { democracia (média) }\end{array}$ & 7,8 & 6,9 & 8,0 & 8,4 & 8,9 & 9,5 & 8,2 & 8,5 & 8,8 \\
\hline $\begin{array}{l}\text { Satisfaçáo com o } \\
\text { sistema político } \\
\text { (média) }\end{array}$ & 4,9 & 5,4 & 2,3 & 6,6 & 3,0 & 6,0 & 4,1 & 4,1 & 6,0 \\
\hline
\end{tabular}

Fonte: Elaborado pelos autores com base nos dados do WVS. 
Com esses resultados, verifica-se que a base eleitoral dos autoritário-populistas é mais insatisfeita com as instituições políticas dos seus países. Com exceção do Chile, onde a desconfiança é maior entre eleitores de outros partidos do que entre os da UDI, nos outros três casos há mais desconfiança institucional entre eleitores autoritário-populistas. $\mathrm{Na}$ Alemanha, a diferença na desconfiança no governo é de $36,8 \%$ entre eleitores da AfD e eleitores de outros partidos, de 39,2\% na desconfiança no parlamento e de $18,4 \%$ nos partidos políticos. Na Holanda, há uma diferença de mais de $30 \%$ na desconfiança no governo e no parlamento para os eleitores dos dois partidos autoritário-populistas. Já no Brasil, a desconfiança generalizada parece estar diluída entre toda a população, tendo em vista que a diferença mais significativa observada é de apenas $10,2 \%$ na desconfiança nos partidos políticos. Portanto, nesses públicos, a perda de legitimidade das instituições políticas relaciona-se à preferência por atores antidemocráticos, autoritários e populistas (GUNTHER e MONTERO, 2003; MOISÉS e MENEGUELLO, 2013).

Assim como na análise longitudinal, a desconfiança institucional não se converte em rejeição à democracia. Nessas duas análises, a média de importância da democracia é maior que oito em quase todos os casos, não havendo diferença significativa entre os eleitorados. Entretanto, verificam-se discrepâncias na avaliaçáo do regime democrático. Como podemos observar, a satisfação com o sistema político é mais elevada entre os eleitores de candidatos que não se enquadram como autoritário-populistas, destacando-se que, no Brasil, o forte descontentamento dos eleitores de Bolsonaro reflete-se nos dados, já que a média de satisfação destes é quase três vezes menor quando comparada a de outros partidos políticos.

\section{Conclusões}

A recente ascensão autoritária-populista chama a atenção pela sua abrangência, e países de todas as regióes do mundo têm experenciado esse fenômeno. Embora Norris e Inglehart (2019) tragam uma explicação para isso, sua análise se limita a países ocidentais desenvolvidos e ao conflito de valores materialistas e pósmaterialistas nessas sociedades. Para responder a esse problema, voltamo-nos à desconexão democrática, por meio da insatisfação política (FOA e MOUNK, 2016). A hipótese foi de que o aumento da desconfiança institucional e da insatisfaçáo com a democracia, na dimensão da demanda do mercado eleitoral, cria um ambiente propício à ascensão de alternativas autoritário-populistas na dimensão da oferta. Para 
tanto, analisamos, a partir de dados da pesquisa World Values Survey e de resultados eleitorais, os casos de Alemanha, Argentina, Brasil, Chile, Espanha e Holanda.

Os dados de insatisfação política demonstram duas tendências diferentes, que juntas indicam a presença de uma desconexáo democrática em quase todos os casos analisados: o forte apoio ao sistema político democrático, com o consenso de que a democracia é algo muito importante, coexistindo com a insatisfação com o desempenho do sistema político e suas instituiçóes. A instabilidade e a falta de confiança institucional podem favorecer a mobilização das massas eleitorais por atores autoritário-populistas e talvez colocar em xeque a própria legitimidade do sistema democrático tal como é hegemônico.

Paralelamente, diversos partidos autoritário-populistas foram criados recentemente ou, quando já existentes, obtiveram melhor desempenho nas últimas eleiçôes. Ao comparar insatisfação política e crescimento do autoritarismo-populista nestes países, encontramos diferentes resultados. Por um lado, nos casos de Brasil e Espanha, verificamos que o aumento da insatisfação política, sobretudo a desconfiança no governo, foi acompanhado pela ascensão eleitoral de Jair Bolsonaro, do PSL e do VOX. Nesses casos, a conjuntura de instabilidade tem levado a populaçáo a desaprovar o desempenho institucional, favorecendo a retórica autoritário-populista desses atores, que ascenderam com a queda da satisfação política. Desta forma, estes casos confirmam a hipótese.

Os casos do Chile e da Argentina são menos concludentes, demonstrando que a hipótese não explica completamente o fenômeno. No Chile, o aumento da insatisfação não se converteu na eleição do candidato autoritário-populista. Entretanto, o UDI participou da coligação do eleito Piñera, que mobilizou a insatisfação institucional e a ambivalência democrática. Assim, atores tradicionais cooptaram a insatisfação que estaria disponível aos atores autoritário-populistas. $\mathrm{Na}$ Argentina, a desconfiança nos partidos políticos e no parlamento também náo resultou em votos para Goméz Centurión e a Frente NOS. A desconfiança institucional argentina coexiste com o apoio à democracia, e a rejeição do passado autoritário na cultura política freia a ascensão desses atores.

Já os casos da Alemanha e da Holanda refutam a hipótese deste artigo. A Alemanha tem os maiores índices de confiança institucional e apoio à democracia, mas teve crescimento no apoio à AfD. Considerando essa disparidade, trata-se de um caso de cultural backlash, tendo em vista que a mobilizaçáo do conservadorismo por esses atores parece estar relacionada às clivagens culturais entre materialistas e pósmaterialistas. Por outro lado, na Holanda, atores autoritário-populistas têm 
mobilizado valores pós-materialistas para justificar agendas extremistas. Portanto, a Holanda é uma exceção à teoria de Norris e Inglehart (2019), e, por isso, estudos futuros precisam investigar como e por que os holandeses têm buscado alternativas autoritário-populistas.

$\mathrm{Na}$ análise da insatisfaçáo política nas bases eleitorais desses atores, constatamos que esses eleitores são extremamente descontentes com as instituiçóes democráticas, embora não rejeitem a democracia em si. Assim, a intensa insatisfação política é um importante fator na preferência por atores autoritário-populistas, mas não é condição suficiente para elegê-los. Isto é, um ambiente de descontentamento é uma condição necessária, mas não suficiente para explicar o avanço desses políticos. Embora a insatisfação seja mobilizada eleitoralmente, e esteja fortemente presente nesses eleitorados, casos menos conclusivos indicam que onde não há insatisfação, a mobilização do conflito de valores é, provavelmente, o fator mais pertinente na conquista de votos.

Por fim, ressaltamos que este trabalho não esgotou as explicaçóes sobre a ascensáo autoritária-populista no mundo, nem mesmo nos países analisados. Ao longo da análise, constatamos que, além da insatisfação política, outros fatores podem explicar este cenário. Pesquisas futuras precisam endereçar as razóes pelo descontentamento político, outros elementos mobilizados pelo autoritarismopopulista, a influência que a cultura política de cada sociedade imprime sobre o mercado eleitoral e, também, analisar além do recorte ocidental.

Henrique Carlos de Oliveira de Castro é Doutor em Ciência Politica, pela Universidade Federal do Rio Grande do Sul (UFRGS). Professor do Programa de Pós-graduação em Ciência Política e do Departamento de Economia e Relações Internacionais da UFRGS. Foi Brazilian Fulbright Distinguished Chair in Democracy and Human Development no Kellogg Institute, University of Notre Dame (EUA) e professor convidado na École des Hautes Études en Sciences Sociales, Paris (França). Membro do Grupo de Trabalho Values 20 (V20). Pesquisador Principal e Diretor Nacional para o Brasil da Pesquisa Mundial de Valores (World Values Survey). Bolsista nivel 2 do CNPq. E-mail: henrique@ufrgs.br.

- Débora de Oliveira Santos é Doutoranda e mestre em Ciência Politica, pela UFRGS. Pesquisadora da Pesquisa Mundial de 
Valores no Brasil (World Values Survey). Bolsista de doutorado do CNPq. E-mail: deboraosantos@ufrgs.br.

- Luana Isabelle Beal é Mestranda em Ciência Politica, pela UFRGS. Pesquisadora da Pesquisa Mundial de Valores no Brasil (World Values Survey). Bolsista de mestrado da CAPES. E-mail: luana.beal@ufrgs.br.

\section{Referências}

ALMOND, Gabriel A.; VERBA, Sidney. The civic culture: political attitudes and democracy in five countries. Princeton: Princeton University Press, 1963.

ALONSO, Daniela; BRUSSINO, Silvina. Cultura política en un escenario electoral de polarización en Argentina. Revista de Psicologia, n. 19, p. 39-59, 2018.

BAQUERO, Marcello. Democracia Inercial: assimetrias entre economia e cultura política na América Latina. Porto Alegre: Editora UFRGS, 2018.

BAQUERO, Marcello; GONZÁLEZ, Rodrigo S. Cultura política, mudanças econômicas e democracia inercial. Uma análise pós-eleições de 2014. Opiniáo Pública, v. 22, n. 3, p. 492-523, 2016.

BAQUERO, Marcello; RANINCHESKI, Sonia; CASTRO, Henrique Carlos de Oliveira de. A formação política do Brasil e o processo de democracia inercial. Revista Debates, v. 12, n. 1, p. 87106, 2018.

BITTENCOURT, Marielli Prestes. A "Nostalgia da Ditadura" e as eleiçóes de 2018 no Brasil: uma proposta explicativa. 2020. Dissertação (Mestrado em Ciência Política) - Programa de PósGraduação em Ciência Política, Universidade Federal do Rio Grande do Sul (UFRGS), Porto Alegre, 2020.

BRIEGER, Pedro. El fenómeno de la marea verde en Argentina. CNN Español, 14 jun. 2018. Disponível em: <cnnespanol.cnn.com/2018/06/14/el-fenomeno-de-la-marea-verde-en-argentina>. Acesso em: 26 set. 2020.

CAPARRÓS, Martín. Vox and the Rise of the Extreme Right in Spain. The New York Times, Nov. 13, 2019. Disponível em: <www.nytimes.com/2019/11/13/opinion/spain-election-vox.html>. Acesso em: 26 set. 2020.

CASTRO, Henrique Carlos de O. de. Democracy vs People: Do Changing Values Challenge Democracy? 2019. In: WAPOR ANNUAL CONFERENCE, 72., 2019, Toronto, Canadá. Anais... Toronto, Canadá, 2019.

CASTRO, Henrique Carlos de O. de. Cultura Política Comparada: democracia e mudanças econômicas: Brasil, Argentina e Chile. Brasília: Verbena, 2014. 
CASTRO, Henrique Carlos de O. de et al. Is Self-expression Chic? Globalisation, Value Change And Convergence In Latin America. Revista Latinoamericana de Opinión Pública, v. 9, n. 2, p. 1-20, nov. 2020.

CHEIBUB, José Antonio. Presidentialism, Parliamentarism, and Democracy. Cambridge: Cambridge University Press, 2007.

COSTA, Maíra Pereira da; GONZÁLEZ, Rodrigo S. Justiça de Transição, Cultura Política e Legado Autoritário no Cone Sul. Revista Sul-Americana de Ciência Política, v. 5, n. 1, p. 125-146, 2019.

CUÉ, Carlos E. Eleição na Espanha tem alta da extrema direita e não destrava caminho para formar Governo. El País, 11 nov. 2019. Disponível em: <brasil.elpais.com/brasil/2019/11/10/internacional/1573402081_937586.html>. Acesso em: 26 set. 2020.

CUÉ, Carlos E.; MONTES, Rocío. Sebastián Piñera: "O Chile perdeu o rumo com Bachelet". El País, 22 abr. 2017.2 Disponível em: <brasil.elpais.com/brasil/2017/04/22/internacional/1492814810_813701.html>. Acesso em: 26 set. 2020.

DALTON, Russel J.; WELZEL, Christian. The civic culture transformed: from allegiant to assertive citizens. New York: Cambridge University Press, 2014.

DAMHUIS, Koen. Why Dutch populists are exceptional: a 'Muslims in the West' reaction essay. Brookins, Dec. 4, 2019. Disponível em: <www.brookings.edu/articles/why-dutch-populists-areexceptional>. Acesso em: 26 set. 2020.

DEMOCRACY and Democratic Values: Dynamics, Measurement, Forecasting. Round Table 1 [Arquivo de áudio]. [Participation] Ronald Inglehart, Pippa Norris, Leonardo Morlino, Robert Worcester, Christian Welzel, Alejandro Moreno, Christian Haerpfer, Marita Carballo, Juan DiezNicolas, Hennie Kotze, Henrique de Castro, Marta Lagos, Ian McAllister. (97 min 28 s). In: WAPOR ANNUAL CONFERENCE, 72., 2019, Toronto, Canadá. Disponível em:<soundcloud.com/user-217208549/round-table-1?fbclid=IwAR3PESXaTg1ivjcbK8L30h-

7Rwuoqq0RpMSNxmksNIyTKi4CpW2O_haMEj0>. Acesso em: 05 nov. 2020.

DUARTE, Jéssica da Silva et al. Effects of economic and political crisis on the rise of conservatism and the far-right. In: WAPOR ANNUAL CONFERENCE, 73., 2020, Salamanca. [Evento online].

EASTON, David. Uma teoria de análise política. Rio de Janeiro: Zahar, 1968.

FOA, Roberto Stefan; MOUNK, Yascha. A desconexão democrática. Journal of Democracy em Português, v. 5, n. 2, p. 1-21, out. 2016.

FREIRE, André. Modelos do comportamento eleitoral: uma breve introdução crítica. Oeiras: Celta Editora, 2001.

FVD throws founder out of the party, citing financial irregularities. Dutch News, Jul. 25, 2019. Disponível em: <www.dutchnews.nl/news/2019/07/fvd-throws-founder-out-of-the-party-citingfinancial-irregularities/>. Acesso em: 26 set. 2020.

GHITIS, Frida. Why the Once-Rising Far Right Is Now Waning in the Netherlands. World Politics Review, Aug. 22, 2019. Disponível em: <www.worldpoliticsreview.com/articles/28142/why-theonce-rising-far-right-is-now-waning-in-the-netherlands>. Acesso em: 26 set. 2020.

GONZÁlEZ, Rodrigo Stumpf. O Método Comparativo e a Ciência Política. Revista de Estudos e Pesquisas sobre as Américas, v. 2, n. 2, jul./dez. 2008. 
GUNTHER, Richard; MONTERO, José Ramón. Legitimidade política em novas democracias. Opiniáo Pública, v. IX, n. 1, p. 1-43, 2003.

HEDGECOE, Guy. Spanish elections: How the far-right Vox party found its footing. $B B C$ News, Nov. 11, 2019. Disponível em: <www.bbc.com/news/world-europe-46422036>. Acesso em: 26 set. 2020

INGLEHART, Ronald. Cultural evolution: people's motivations are changing, and reshaping the world. New York: Cambridge University Press, 2018.

INGLEHART, Ronald. Political dissatisfaction and mass support for social change in advanced industrial society. Comparative Political Studies, v. 10, n. 3, p. 455-472, Oct. 1977.

INGLEHART, Ronald; WELZEL, Christian. Modernização, mudança cultural e democracia: a sequência do desenvolvimento humano. Brasília: Verbena, 2014.

JUAN JOSÉ Gómez Centurión, sobre los desaparecidos: "No es lo mismo 8.000 verdades que 22.000 mentiras”. La Nación, 29 jan. 2017. Disponível em: <www.lanacion.com.ar/politica/juan-josegomez-centurion-sobre-los-desaparecidos-son-22-mil-mentiras-nid1980180/>. Acesso em: 26 set. 2020.

KYLE, Jordan; GULTCHIN, Limor. Populists in Power Around the World. 2018. Disponível em: $<$ institute.global/policy/populists-power-around-world>. Acesso em: 13 nov. 2020.

LA JUSTICIA sobreseyó a Gómez Centurión por sus dichos negacionistas sobre la dictadura. Política Argentina, 22 mayo 2017. Disponível em: <www.politicargentina.com/notas/201705/21057-lajusticia-sobreseyo-a-gomez-centurion-por-sus-dichos-negacionistas-sobre-la-dictadura.html>. Acesso em: 26 set. 2020.

LIMA, Wilson. Aliança pelo Brasil: por que o novo partido de Bolsonaro ainda não saiu do papel. Gazeta do Povo, 24 ago. 2020. Disponível em: <www.gazetadopovo.com.br/republica/alianca-pelobrasil-por-que-o-novo-partido-de-bolsonaro-ainda-nao-saiu-do-papel/>. Acesso em: 26 set. 2020.

LOPES, Denise M. N. Nascimento. Para pensar a Confiança e a Cultura Política na América Latina. Opinião Pública, v. X, n. 1, p. 162-187, 2004.

MANDER, Benedict. Piñera faces battle to push reforms through Chile congress. Financial Times, 2017. Disponível em: <www.ft.com/content/01115b20-e3ff-11e7-97e2-916d4fbac0da>. Acesso em: 26 set. 2020.

MOISÉS, José Álvaro. Cultura política, instituiçôes e democracia: liçōes da experiência brasileira. Revista Brasileira de Ciências Sociais, v. 23, n. 66, p. 11-46, 2008.

MOISÉS, José Álvaro; MENEGUELLO, Rachel. A desconfiança política e os seus impactos na qualidade da democracia. São Paulo: Editora da Universidade de São Paulo, 2013.

NORRIS, Pippa; INGLEHART, Ronald. Cultural backlash: Trump, Brexit, and authoritarian populism. New York: Cambridge University Press, 2019.

POWER, Timothy J.; JAMISON, Giselle D. Desconfiança política na América Latina. Opinião Pública, v. 11, n. 1, p. 65-93, 2005.

PUTNAM, Robert D.; LEONARDI, Robert; NANETTI, Raffaella Y. Institutional Performance and Political Culture: Some Puzzles about the Power of the Past. Governance: An International Journal of Policy and Administration, v. 1, n. 3, p. 221-242, July 1988.

REYNA, Zenaida M. G. Interpretaciones sobre la cultura política del peronismo en Argentina. Papel Politico, v. 12, n. 2, p. 347-368, 2007. 
SANTOS, Débora de Oliveira et al. Brazilian political culture: Bolsonaro's election and vote behavior. In: WAPOR ANNUAL CONFERENCE, 73., 2020, Salamanca. [Evento online].

SARTORI, Giovanni. Comparación y método comparativo. In: SARTORI, Giovanni; MORLINO, Leonardo. La comparación en las ciencias sociales. Madrid: Alianza, 1991. p. 29-49.

UNA RENOVADA marea verde en Argentina para lograr el aborto legal en 2020. Agência EFE, 20 fev. 2020. Disponível em: <www.efe.com/efe/america/sociedad/una-renovada-marea-verde-enargentina-para-lograr-el-aborto-legal-2020/20000013-4177715>. Acesso em: 26 set. 2020.

WORLD VALUES SURVEY. Time Series Data. All Rounds - Country-Pooled Datafile Version. 2020. Disponível em: <https://www.worldvaluessurvey.org/WVSDocumentationWVL.jsp>. Acesso em: 26 set. 2020.

Texto recebido em 25 de novembro de 2020. Aprovado em $1^{\circ}$ de dezembro de 2020. 